\title{
Canine Platelet-Rich Plasma Systems: A Prospective Analysis
}

\author{
Brittany Jean Carr ${ }^{1}$, Sherman O. Canapp $\mathrm{Jr}^{1 *}$, David R. Mason ${ }^{2}$, Catherine Cox ${ }^{1}$ and \\ Theresa Hess ${ }^{2}$ \\ ${ }^{1}$ Veterinary Orthopedic and Sports Medicine, Annapolis Junction, MD, USA, ${ }^{2}$ Las Vegas Veterinary Specialty Center, \\ Las Vegas, NV, USA
}

Objective: To quantitate key parameters of the platelet-rich plasma (PRP) product from five commercial canine PRP systems in healthy, adult canines.

Materials and Methods: A prospective study was performed from January 2013 to April 2014. Five commercial systems were analyzed using 10 healthy dogs per system. ${ }^{1-5}$ Blood was obtained according to the manufacturer's protocol for each system. The mean baseline whole blood platelet, RBC, WBC, neutrophil, monocyte, and lymphocyte concentrations were determined for each PRP system. All blood samples were processed according to the manufacturer's protocols. The mean PRP product platelet, RBC, WBC, neutrophil, monocyte, and lymphocyte concentrations were determined for each PRP system. These values were then compared to the mean baseline values. Comparisons

OPEN ACCESS

Edited by:

Fausto Cremonesi,

Università degli Studi di Milano, Italy

Reviewed by:

Diego Celdran,

University of Arizona, USA

Valerie Johnson,

Colorado State University, USA

*Correspondence:

Sherman O. Canapp Jr scanapp@vosm.com

Specialty section:

This article was submitted to Veterinary Regenerative Medicine, a section of the journal Frontiers in Veterinary Science

Received: 26 September 2015 Accepted: 27 November 2015 Published: 05 January 2016

Citation:

Carr BJ, Canapp SO Jr, Mason DR,

Cox $C$ and Hess $T$ (2016) Canine Platelet-Rich Plasma Systems:

A Prospective Analysis.

Front. Vet. Sci. 2:73.

doi: 10.3389/fvets.2015.00073 of mean whole blood and mean PRP product parameters were calculated using a paired $t$-test with significance established at $p=0.05 .^{6}$

Results: Platelet concentration was significantly increased for System $1 \quad(p=0.0088)$ and System $3(p<0.0001)$, and was significantly decreased for System $2(p<0.0001)$. All five systems significantly decreased the red blood cell concentration $(p<0.0001$ for each system comparison). Neutrophil concentration was significantly decreased for System 2, System 3, and System 4 ( $p<0.0001$ for each system comparison). Neutrophil concentration was significantly increased for System $5(p=0.0089)$.

Clinical Relevance: The systems with the highest platelet yield were System 1 and System 3. System 3 increased platelet concentration while significantly reducing the RBC and neutrophil concentrations. Further study is indicated to assess the efficacy of PRP therapy in canines, the efficacy of canine PRP systems, and the clinical applications for PRP therapy in dogs.

Keywords: platelet-rich plasma, autologous conditioned plasma, leukocyte-rich platelet-rich plasma, leukocytepoor platelet-rich plasma, platelet count

\footnotetext{
Abbreviations: ACP, autologous conditioned plasma; LP-PRP, leukocyte-poor platelet-rich plasma; LR-PRP, leukocyte-rich platelet-rich plasma; PRP, platelet-rich plasma; RBC, red blood cell; WBC, white blood cell.

${ }^{1}$ SmartPReP ${ }^{\circledR} 2$ ACP + , Harvest Technologies, Corp, Plymouth, MA, USA.

${ }^{2}$ Arthrex ACP, Arthrex Orthobiologics, Naples, FL, USA.

${ }^{3}$ CRT Pure PRP, Canine Regenerative Therapies, Fort Meyers, FL, USA.

${ }^{4}$ ProTec PRP, Pulse Veterinary Technologies, LLC, Alpharetta, GA, USA.

${ }^{5}$ C-PET Canine Platelet Enhancement Therapy, Pall Corporation, Port Washington, NY, USA.

${ }^{6}$ Las Vegas Veterinary Specialty Center, Las Vegas, NV, USA.
} 


\section{INTRODUCTION}

Platelet-rich plasma (PRP) is an autogenous fluid concentrate composed primarily of platelets and growth factors. Recent studies have shown PRP to mediate healing by supplying growth factors, cytokines, chemokines, and other bioactive compounds (1-7). Initially, PRP's first clinical applications were limited to dentistry and maxillofacial surgery to improve bone healing. However, PRP currently has much broader clinical applications, extending to orthopedic surgery and sports medicine. Recent studies have shown PRP to be efficacious in managing many different orthopedic conditions, including osteoarthritis and soft tissue injuries $(3,4,7-31)$.

Platelets play roles in both hemostasis and wound healing. Platelets contain granules that release growth factors to stimulate other cells of the body to migrate to the area of trauma, thus facilitating tissue healing. It is the growth factors contained within the platelets that are of significance for tissue healing. These growth factors include platelet-derived growth factor (PDGF), transforming growth factor- $\beta 1$ (TGF- $\beta 1$ ), transforming growth factor- $\beta 2$ (TGF- $\beta 2$ ), vascular endothelial growth factor (VEGF), basic fibroblastic growth factor (bFGF), and epidermal growth factor (EGF) $(1-4,6)$. Many of the growth factors found in PRP have been shown to act either individually or synergistically to enhance cellular migration and proliferation, angiogenesis, and matrix deposition to promote tendon and wound healing, aid in bone healing, and counteract the cartilage breakdown that is associated with osteoarthritis $(2-8,10,13,19,22,26,29,31)$ Thus, PRP has been used to manage many different orthopedic conditions. A number of studies have supported the use of PRP for soft tissue healing $(10,11,19-21,24-27,30)$. A recent double-blinded, randomized controlled trial showed that patients with patellar tendinopathy treated with PRP had greater function and less pain than patients in the control group (11). Multiple studies have also documented the use of PRP for management of osteoarthritis $(7,8,12-18,22,23)$. One recent prospective, blinded, randomized trial showed a single dose of PRP to be more effective than a placebo for improving function in humans with knee osteoarthritis (22). Furthermore, recent studies have also shown that platelets recruit, stimulate, and provide a scaffold for stem cells, supporting its use with stem cells to stimulate healing (27, 31-39). Hence, PRP has also been used in conjunction with stem cell therapy to aid in cartilage, bone, and soft tissue healing.

Multiple formulations of PRP have been developed and studied. Previous studies in humans have reported that the ideal PRP product should have anywhere from a four- to sevenfold increase in platelets $(2-4,6)$. However, platelet concentration is not the only important component of a PRP product. Inclusion or exclusion of mononuclear cells, neutrophils, and red blood cells not only define an autologous platelet product but have also been reported to affect the clinical efficacy of the product and play major roles affecting the inflammatory responses after PRP injection $(2,5$, $10,19-22,40-44)$. In general, it is believed that red blood cells and neutrophils should be reduced as they have an inflammatory effect, while the effect of mononuclear cells remains largely unknown $(36,40,41,45-48)$.
Multiple commercial PRP separation systems have been developed for both human and equine use. PRP products from different commercially available PRP separation systems often have variations in their concentrations of platelets, $\mathrm{WBC}$, and growth factors $(6,43)$. Furthermore, while these systems may have been previously validated for human and/or equine use, there is limited research supporting their validation of a PRP system for canine use. In fact, a recent study revealed that PRP systems validated for human and/or equine use may not yield similar or consistent results in the canine (44). Another recent study evaluated some of the commercial canine PRP systems and also found inconsistent results; however, this study failed to perform statistical analysis and WBC differential on the PRP products (49). The purpose of this study was to compare key parameters of the PRP product from five of the most commonly used commercial canine PRP systems in healthy, adult canines.

\section{MATERIALS AND METHODS}

A prospective study involving two small animal surgery specialty centers was performed from January 2013 to April 2014. In accordance with AAALAC International Rules of Accreditation, this study was performed with the approval of the VOSM Research Committee and with owner consent. In this study, all dogs who participated were client-owned dogs deemed healthy by a veterinarian. All clients volunteered their dog for the study and provided written consent as required by Veterinary Orthopedic and Sports Medicine Group for every study participant. All dogs that participated in the study were directly overseen by a veterinarian to ensure no harm was incurred during study participation.

The following five commercial systems were prospectively analyzed and labeled as follows: System $1,{ }^{1}$ System $2,{ }^{2}$ System $3,{ }^{3}$ System $4,{ }^{4}$ and System $5 .{ }^{5}$ Data for Systems 1,3 , and 4 were collected at Center $1,{ }^{7}$ while data for Systems 2 and 5 were collected at Center 2 (See footnote 6). Ten adult, healthy dogs with no known previous or current medical problems were used for each PRP system. Two of the canines were used for both System 3 and System 4. In this case, the blood samples were collected on separate days, 30 days apart from each other. One investigator was appointed at each center to perform blood collection and sample processing. The required volume of blood was then obtained from each dog according to the manufacturer's protocol and specifications for each PRP system (Table 1). For System 1, System 2, System 3, and System 5, all blood samples were obtained from the jugular vein using an 18 -gage-butterfly needle. All blood samples for System 4 were collected from the jugular vein; however, System 4 required the use of a 21-gage-butterfly needle vacutainer as blood was collected directly into the sodium citrate tubes provided by the manufacturer for processing. A baseline blood WBC differential, RBC concentration, and platelet concentration were obtained on all dogs using an in-house hematology analyzer that had been calibrated according to manufacturer standards. ${ }^{8}$

\footnotetext{
${ }^{7}$ Veterinary Orthopedic and Sports Medicine Group, Annapolis Junction, MD, USA.

${ }^{8}$ Idexx LaserCyte Hematology Analyzer, Idexx Laboratories, Westbrook, ME, USA.
} 
TABLE 1 | PRP system protocols summary.

\begin{tabular}{|c|c|c|c|c|c|c|}
\hline System & $\begin{array}{c}\text { Centrifugation or } \\
\text { filtration }\end{array}$ & $\begin{array}{l}\text { Volume of } \\
\text { blood required }\end{array}$ & Anticoagulant & $\begin{array}{c}\text { Volume of } \\
\text { anticoagulant }\end{array}$ & $\begin{array}{c}\text { Size of } \\
\text { syringe used }\end{array}$ & $\begin{array}{l}\text { PRP product } \\
\text { volume }\end{array}$ \\
\hline 1 & Centrifugation & $50 \mathrm{~mL}$ & ACD-A & $10 \mathrm{~mL}$ & $60 \mathrm{~mL}$ & $10 \mathrm{~mL}$ \\
\hline 2 & Centrifugation & $16 \mathrm{~mL}$ & ACD-A & $1.5 \mathrm{~mL}$ & $20 \mathrm{~mL}$ & $4-7 \mathrm{~mL}$ \\
\hline 3 & Centrifugation & $50 \mathrm{~mL}$ & ACD-A & $10 \mathrm{~mL}$ & $60 \mathrm{~mL}$ & $4 \mathrm{~mL}$ \\
\hline 4 & Centrifugation & $9 \mathrm{~mL}$ & Sodium citrate & $1 \mathrm{~mL}$ & $\mathrm{n} / \mathrm{a}$ & $4-5 \mathrm{~mL}$ \\
\hline 5 & Filtration & $55 \mathrm{~mL}$ & ACD-A & $5 \mathrm{~mL}$ & $60 \mathrm{~mL}$ & $6-8 \mathrm{~mL}$ \\
\hline
\end{tabular}

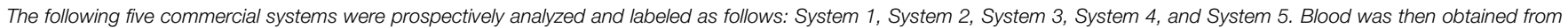
each dog according to the manufacturer's protocol and specifications for each PRP system. This table summarizes the main characteristics of each system's protocol.

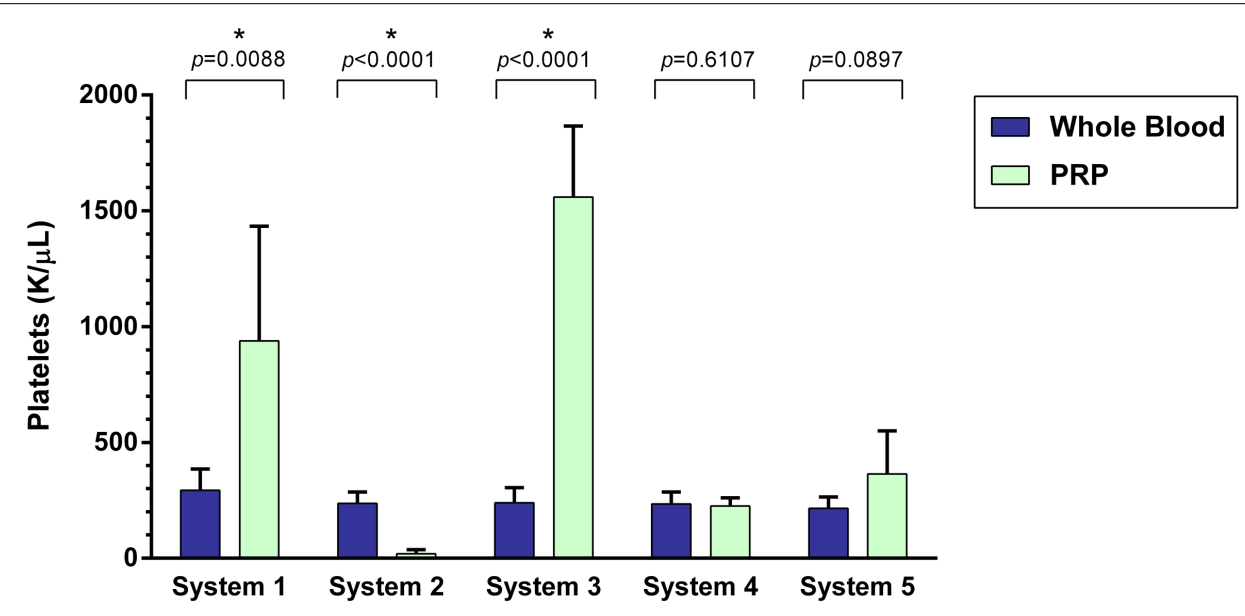

FIGURE 1 | Comparison of mean whole blood and mean PRP product platelet concentrations between five commercial PRP systems. An asterisk ( $\left.{ }^{\star}\right)$ indicates a statistically significant difference between the mean whole blood and mean PRP product for that PRP system. Bars represent mean $\pm 95 \% \mathrm{Cl}(n=10)$.

The mean baseline whole blood platelet, RBC, WBC, neutrophil, monocyte, and lymphocyte concentrations were determined for each PRP system. Baseline concentrations were obtained immediately following blood draw for all dogs. All blood samples were processed immediately following blood draw according to the protocols established by the manufacturer. PRP product concentrations were obtained immediately following processing. The platelet, RBC, WBC, neutrophil, monocyte, and lymphocyte concentrations were obtained for all processed samples. The mean PRP product platelet, RBC, WBC, neutrophil, monocyte, and lymphocyte concentrations were determined for each PRP system. The D'Agostino \& Pearson Omnibus normality test was performed on the differences between PRP and Whole Blood for each data set with significance established at $p=0.01$. All data sets were found to be normally distributed. Data were then analyzed using a paired $t$-test. These values were analyzed using statistical software. ${ }^{9}$ Significance was established at $p=0.05$.

\section{RESULTS}

Blood was obtained from a total of 48 different healthy, adult canines. The following breeds were represented: Labrador Retriever $(n=7)$, Border Collie $(n=5)$, German Shepherd Dog

${ }^{9}$ GraphPad Prism 6, GraphPad Software Inc, La Jolla, CA, USA. $(n=4)$, Golden Retriever $(n=4)$, Rottweiler $(n=3)$, Boxer Dog $(n=2)$, Doberman $(n=2)$, English Bulldog $(n=2)$, Pit Bull Terrier $(n=2)$, American Bulldog $(n=1)$, American Staffordshire Terrier $(n=1)$, Belgian Malinois $(n=1)$, Collie $(n=1)$, French Bulldog $(n=1)$, Great Dane $(n=1)$, Keeshond $(n=1)$, Mastiff $(n=1)$, Newfoundland $(n=1)$, Standard Poodle $(n=1)$, Vizsla $(n=1)$, and mixed canine $(n=6)$. There were 6 intact males, 17 neutered males, 8 intact females, and 17 spayed females. The mean weight was $31.6 \mathrm{~kg}$ (range $11.3-55.5 \mathrm{~kg}$ ). The mean age was 6.2 years old (range $1-13$ years old).

\section{Platelet Concentration}

A statistically significant difference was found between the mean whole blood and mean PRP product platelet concentrations of System 1, System 2, and System 3 (Figure 1). Mean platelet concentration was significantly increased for System $1(p=0.0088)$, which was a $219 \%$ increase, and for System $3(p<0.0001)$, a $550 \%$ increase. Mean platelet concentration was significantly decreased for System $2(p<0.0001)$, which was a 91\% decrease. There was no statistically significant change in mean platelet concentration for System $4(p=0.6107)$ and System $5(p=0.0897)$.

\section{RBC Concentration}

A statistically significant difference was found between the mean whole blood and mean PRP product RBC concentrations of all 
five PRP systems (Figure 2). Mean RBC concentration was significantly decreased for System $1(p<0.0001)$, System $2(p<0.0001)$, System $3(p<0.0001)$, System $4(p<0.0001)$, and System 5 $(p<0.0001)$. System 2 was found to have the greatest decrease in RBC concentration (98\%), followed by System 4 (96\%), System 3 (95\%), System 1 (85\%), and System 5 (37\%).

\section{WBC Concentration}

A statistically significant difference was found between the mean whole blood and mean PRP product WBC concentrations of System 2, System 4, and System 5 (Figure 3). Mean WBC concentration was significantly decreased for System $2(p<0.0001)$ and System $4(p<0.0001)$, an $89 \%$ decrease for both systems. Mean WBC concentration was significantly increased for System $5(p=0.0005)$, which is a $110 \%$ increase. There was no statistically significant change in mean WBC concentration for System 1 $(p=0.2161)$ and System $3(p=0.3439)$.

\section{Neutrophil Concentration}

A statistically significant difference was found between the mean whole blood and mean PRP product neutrophil concentrations of System 2, System 3, System 4, and System 5 (Figure 4). Mean neutrophil concentration was significantly decreased for System $2(p<0.0001)$, System $3(p<0.0001)$, and System $4(p<0.0001)$. System 2 yielded a $90 \%$ decrease, System 3 yielded an $85 \%$ decrease, and System 4 yielded a $98 \%$ decrease in mean neutrophil concentration compared to mean whole blood values. Mean neutrophil concentration was significantly increased for System $5(p=0.0089)$, a $59 \%$ increase. There was no statistically significant change in mean neutrophil concentration for System 1 $(p=0.9300)$.

\section{Monocyte Concentration}

A statistically significant difference was found between the mean whole blood and mean PRP product monocyte concentrations of System 2, System 4, and System 5 (Figure 5). Mean monocyte concentration was significantly decreased for System $2(p=0.0064)$, which was a $62 \%$ decrease, and for System $4(p<0.0001)$, a $79 \%$ decrease. Mean monocyte concentration was significantly increased for System 5 ( $p=0.0032$ ), a 114\% increase. There was no statistically significant change in mean neutrophil concentration for System $1(p=0.1245)$ and System $3(p=0.7759)$.

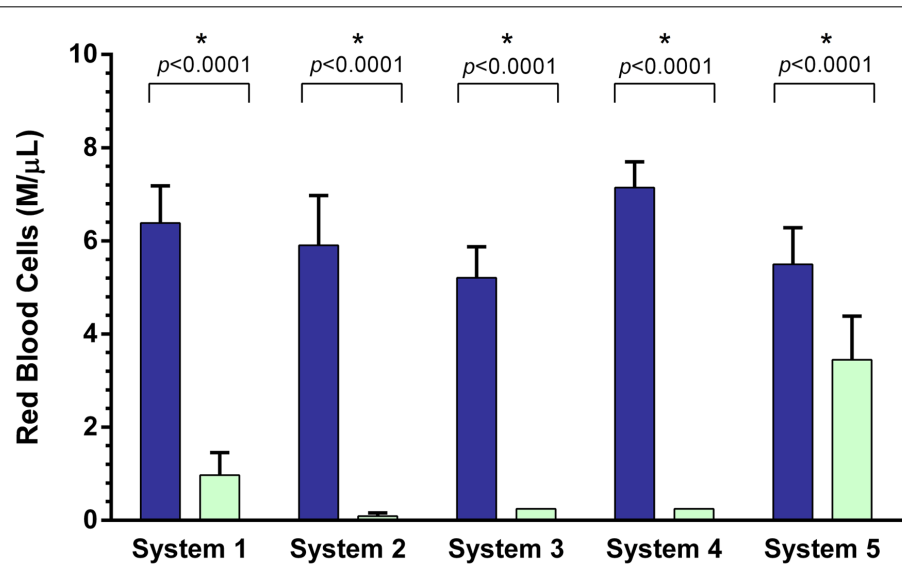

FIGURE 2 | Comparison of mean whole blood and mean PRP product RBC concentrations between five commercial PRP systems. An asterisk (*) indicates a statistically significant difference between the mean whole blood and mean PRP product for that PRP system. Bars represent mean $\pm 95 \% \mathrm{Cl}(n=10)$.

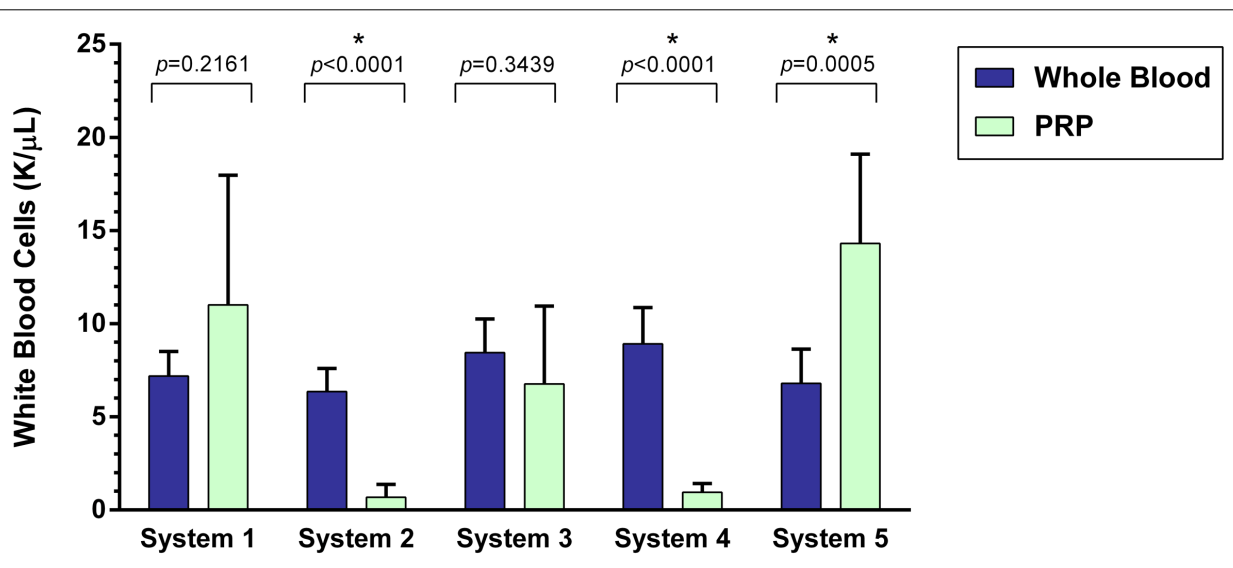

FIGURE 3 | Comparison of mean whole blood and mean PRP product WBC concentrations between five commercial PRP systems. An asterisk (*) indicates a statistically significant difference between the mean whole blood and mean PRP product for that PRP system. Bars represent mean $\pm 95 \% \mathrm{Cl}(n=10)$. 


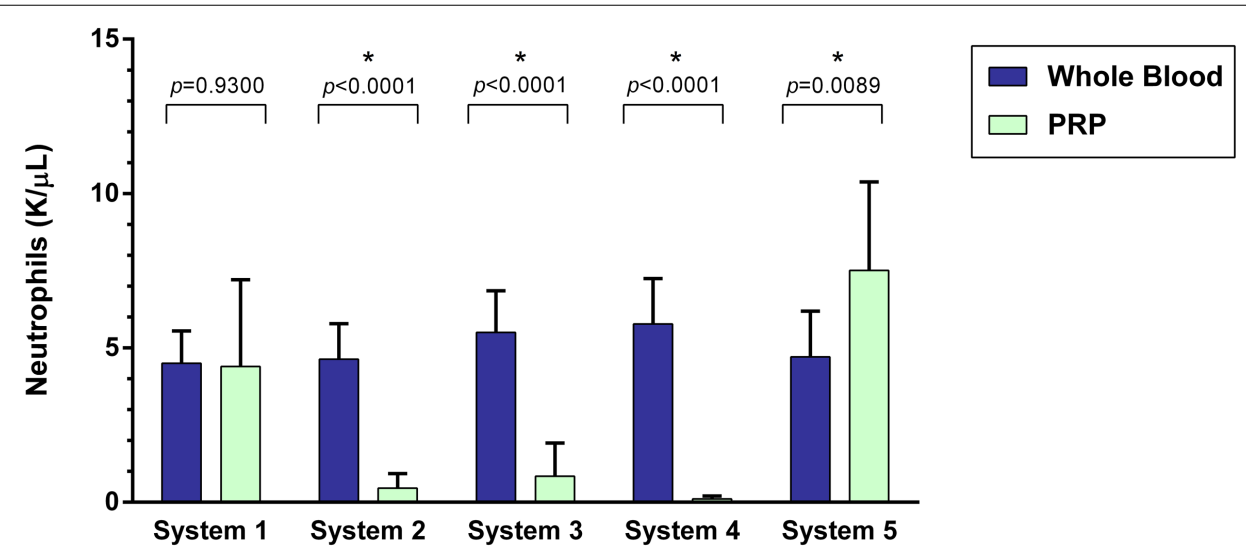

FIGURE 4 | Comparison of mean whole blood and mean PRP product neutrophil concentrations between five commercial PRP systems. An asterisk $\left(^{\star}\right)$ indicates a statistically significant difference between the mean whole blood and mean PRP product for that PRP system. Bars represent mean $\pm 95 \%$ Cl $(n=10)$.

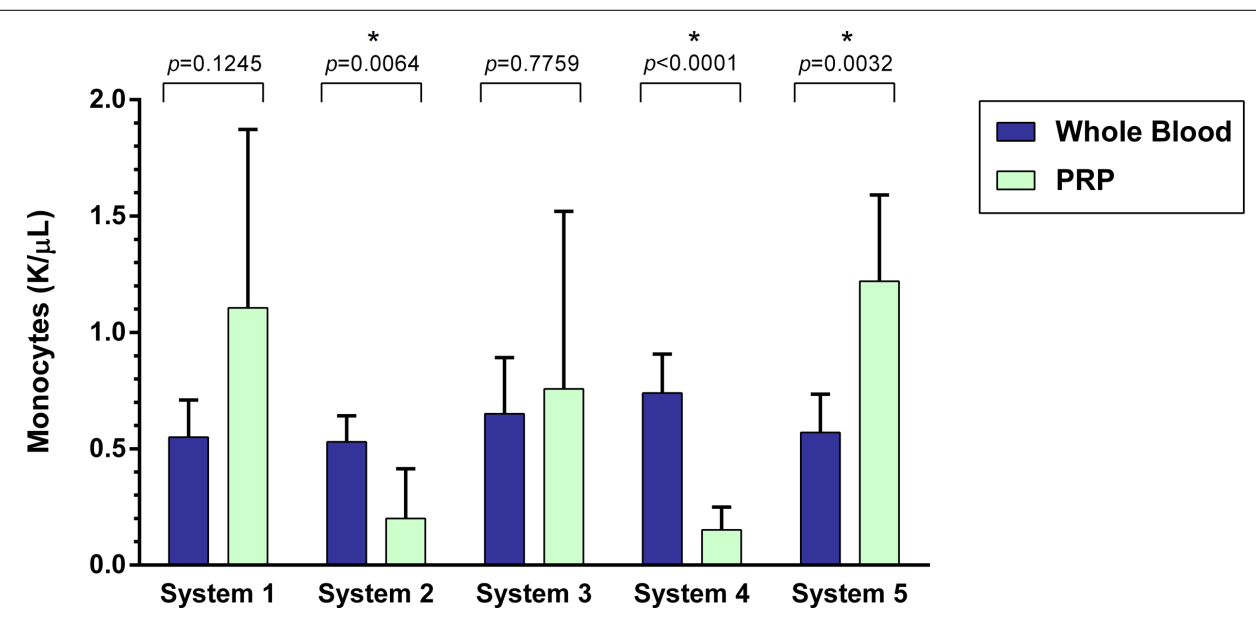

FIGURE 5 | Comparison of mean whole blood and mean PRP product monocyte concentrations between five commercial PRP systems. An asterisk (*) indicates a statistically significant difference between the mean whole blood and mean PRP product for that PRP system. Bars represent mean $\pm 95 \% \mathrm{Cl}(n=10)$.

\section{Lymphocyte Concentration}

A statistically significant difference was found between the mean whole blood and mean PRP product lymphocyte concentrations of all five PRP systems (Figure 6). Mean lymphocyte concentration was significantly decreased for System $2(p=0.0004)$, which is a $74 \%$ decrease, and System $4(p=0.0004)$, a $67 \%$ decrease. Mean lymphocyte concentration was significantly increased for System $1(p=0.0494)$, System $3(p=0.0260)$, and System $5(p=0.0013)$. System 1 yielded a $191 \%$ increase, System 3 a 220\% increase, and System 5 a 267\% increase in mean lymphocyte concentration compared to mean whole blood values.

\section{DISCUSSION}

Platelet-rich plasma concentration results varied among systems. The systems with the highest platelet yield were System 1 and System 3. However, while System 1 yielded a 219\% mean increase in platelets and $85 \%$ decrease in RBC from baseline, this system failed to reduce neutrophil concentrations. System 3 yields a $550 \%$ mean increase in platelets while removing $>95 \%$ of the RBC and $85 \%$ of neutrophils.

Multiple formulations of PRP have been developed and studied. Previous studies in humans have reported that the ideal PRP product should have anywhere from a four- to sevenfold increase in platelets $(2-4,6)$. However, platelet concentration is not the only important component of a PRP product. Inclusion or exclusion of mononuclear cells, neutrophils, and red blood cells not only define an autologous platelet product, but have also been reported to affect the clinical efficacy of the product and play major roles affecting the inflammatory responses after PRP injection $(2,5,10$, $19-22,40-44)$. In this study, the systems with the highest platelet yield were System 1 and System 3.

Reducing RBC concentration is thought to be important when developing the ideal PRP product (40). A recent study revealed an increased RBC concentration in PRP increases the concentrations of unwanted inflammatory mediators, specifically IL-1 and TGF$\alpha$. This study also showed that synoviocytes treated with RBC concentrate demonstrated significantly more synoviocyte death when compared with leukocyte-rich PRP (LR-PRP), leukocyte-poor 

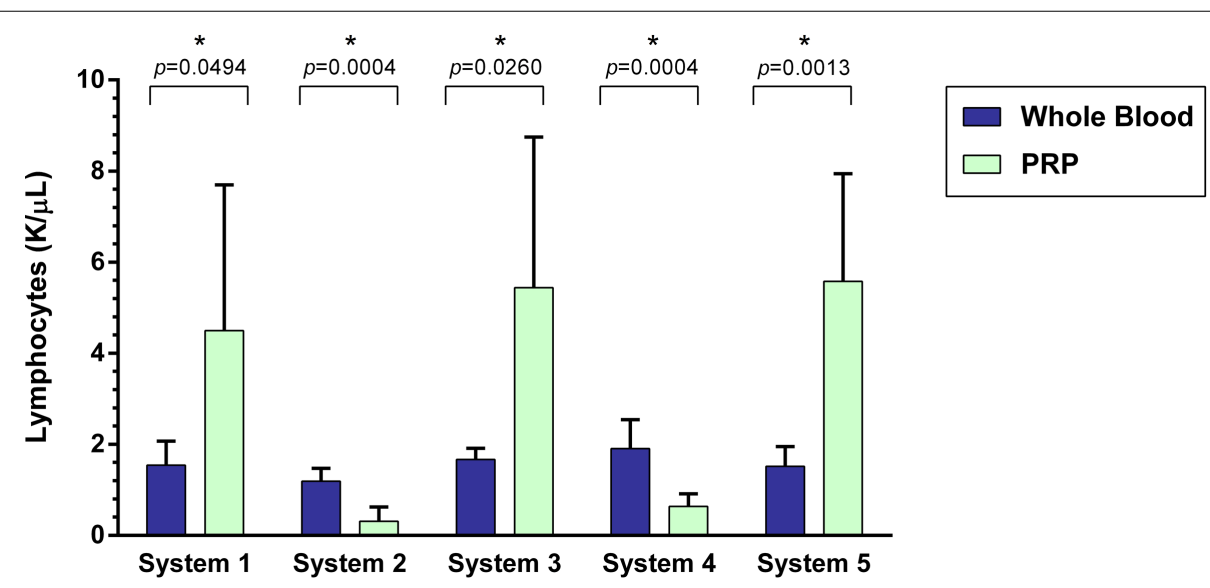

FIGURE 6 | Comparison of mean whole blood and mean PRP product lymphocyte concentrations between five commercial PRP systems. An asterisk $\left(^{\star}\right)$ indicates a statistically significant difference between the mean whole blood and mean PRP product for that PRP system. Bars represent mean $\pm 95 \%$ Cl $(n=10)$

PRP (LP-PRP), and phosphate-buffered saline (PBS) (40). In this study, all five canine PRP systems significantly decreased the RBC concentration.

The effect of leukocyte concentration in PRP products has also been investigated. Both LR-PRP and LP-PRP have been studied and compared. Recent studies have shown LR-PRP is associated with increased pro-inflammatory mediators, including IL-1 $\beta$, IL6 , IL- 8 IFN- $\gamma$, and TNF- $\alpha(1,2,5,10,40,41)$. Increased leukocytes in PRP are also associated with more metalloproteinase (MMP3 and MMP-13) gene expression and less cartilage oligomeric matrix protein (COMP) and decorin gene expression (10, 36, 45). These potentially deleterious effects are largely attributed to the presence of neutrophils. Additionally, an increased concentration of neutrophils in PRP is also positively correlated with an increased MMP-9 concentration which degrades collagen and other extracellular matrix molecules $(20,36,41,45)$. One recent study has shown LR-PRP causes significantly more synoviocyte death when compared with LP-PRP and PBS (40). Thus, LP-PRP has been thought to be more beneficial than LR-PRP in maintaining tendon homeostasis and counteract inflammation associated with osteoarthritis $(10,19,20,40,45)$. Of the systems with the highest platelet yield (System 1 and System 3), System 1 failed to reduce WBC concentration and neutrophil concentrations, while System 3 removed greater than 19\% of WBC and $85 \%$ of neutrophils.

While an increased neutrophil concentration in PRP is known to have negative effects, the effect of monocytes and lymphocytes remains largely unknown. There was great variation in this study of monocyte and lymphocyte concentrations in the final PRP product. Recent studies suggest that monocytes are associated with an increase in cellular metabolism and collagen production in fibroblasts and a decrease in release of anti-angiogenic cytokines interferon- $\gamma$ and IL-12 $(47,48)$. Platelets have also been shown to activate peripheral blood mononuclear cells (lymphocytes, monocytes, and macrophages) to help stimulate collagen production, which is believed to be mediated by an increase in IL-6 expression $(47,48)$. However, the role of monocytes and lymphocytes in PRP therapy remains unclear and further investigation is warranted.
When compared to the previous study evaluating platelet concentration of PRP products from various canine commercial systems, our study found similar results (49). Three of the commercial systems were tested in both studies. PRP product platelet concentrations and total WBC concentrations were similar between both studies. However, the previous study failed to perform WBC differentiation on the PRP products, so no comparisons can be made regarding neutrophil, lymphocyte, or monocyte concentrations.

Limitations of this study include small sample size and limitations inherent to its design. Different dogs were used for each PRP system, and while all dogs were confirmed to be healthy, one cannot assume that the dogs used are representative of the entire canine population. Ideally, the same dog would be used for all systems and all blood samples would be drawn at the same time to eliminate variation in hematological composition. We attribute the variation in results to this as well as inherent patient factors. However, it was not possible to use the same dogs for simultaneous sample collection and processing as the study was conducted at two separate centers. Furthermore, it was also not feasible to obtain the large blood sample required for all systems to be tested simultaneously.

The goal of this study was to compare key parameters of the PRP product from five commercial canine PRP systems in healthy, adult canines. No claims regarding the efficacy of PRP therapy in canines or the efficacy of the PRP formulations evaluated can be deduced from this study. Further study is indicated to assess the concentrations of growth factors and cytokines in the commercial canine PRP products and to determine the concentration of platelets and growth factors required for therapeutic effect. Further study is also needed to evaluate the efficacy of PRP therapy and further define its clinical applications in canines.

\section{AUTHOR CONTRIBUTIONS}

All authors assisted with study development, procedures, data analysis, and manuscript preparation. 


\section{REFERENCES}

1. Boswell SG, Cole BJ, Sundman EA, Karas V, Fortier LA. Platelet-rich plasma: a milieu of bioactive factors. Arthroscopy (2012) 28(3):429-39. doi:10.1016/j. arthro.2011.10.018

2. Dohan Ehrenfest DM, Doglioli P, de Peppo GM, Del Corso M, Charrier JB. Choukroun's platelet-rich fibrin (PRF) stimulates in vitro proliferation and differentiation of human oral bone mesenchymal stem cell in a dose-dependent way. Arch Oral Biol (2010) 55:185-94. doi:10.1016/j.archoralbio.2010.01.004

3. Filardo G, Kon E, Roffi A, Di Matteo B, Merli ML, Marcacci M. Platelet rich plasma: why intra-articular? A systematic review of preclinical studies and clinical evidence on PRP for joint degeneration. Knee Surg Sports Traumatol Arthrosc (2013) 23(9):2459-74. doi:10.1007/s00167-013-2743-1

4. Hsu WK, Mishra A, Rodeo SR, Fu F, Terry MA, Randelli P, et al. Plateletrich plasma in orthopaedic applications: evidence-based recommendations for treatment. J Am Acad Orthop Surg (2013) 21:739-48. doi:10.5435/JAAOS-2112-739

5. McLellan J, Plevin S. Does it matter which platelet-rich plasma we use? Equine Vet Educ (2011) 23(2):101-4. doi:10.1111/j.2042-3292.2010.00185.x

6. Pelletier MH, Malhotra A, Brighton T, Walsh WR, Underman R. Platelet function and constituents of platelet rich plasma. Int J Sports Med (2013) 34:74-80. doi:10.1055/s-0032-1316319

7. Sundman EA, Cole BJ, Karas V, Valle CD, Tetreault MW, Mohammed HO, et al. The anti-inflammatory and matrix restorative mechanisms of plateletrich plasma in osteoarthritis. Am J Sports Med (2013) 42(1):35-41. doi:10.1177/ 0363546513507766

8. Abrams GD, Frank RM, Fortier LA, Cole BJ. Platelet-rich plasma for articular cartilage repair. Sports Med Arthrosc Rev (2013) 21:213-9. doi:10.1097/JSA. 0b013e3182999740

9. Cho K, Kim JM, Kim MH, Kang SS, Kim G, Choi SH. Scintigraphic evaluation of osseointegrative response around calcium phosphate-coated titanium implants in tibia bone: effect of platelet-rich plasma on bone healing in dogs. Eur Surg Res (2013) 51:138-45. doi:10.1159/000357197

10. Dragoo JL, Braun HJ, Durham JL, Ridle BA, Odegaard JI, Luong R, et al. Comparison of the acute inflammatory response of two commercial plateletrich plasma systems in healthy rabbit tendons. Am J Sports Med (2012) 40(6):1274-81. doi:10.1177/0363546512442334

11. Dragoo JL, Wasterlain AS, Braun HJ, Nead KT. Platelet-rich plasma as a treatment for patellar tendinopathy: a double-blind, randomized controlled trial. Am J Sports Med (2014) 42(3):610-8. doi:10.1177/0363546513518416

12. Filardo G, Kon E, Di Martino A, Di Matteo B, Merli ML, Cenacchi A, et al. Platelet-rich plasma vs hyaluronic acid to treat knee degenerative pathology: study design and preliminary results of a randomized controlled trial. BMC Musculoskelet Disord (2012) 13:229. doi:10.1186/1471-2474-13-229

13. Filardo G, Kon E, Buda R, Timoncini A, Di Martino A, Cenacchi A, et al. Platelet-rich plasma intra-articular knee injections for the treatment of degenerative cartilage lesions and osteoarthritis. Knee Surg Sports Traumatol Arthrosc (2011) 19:528-35. doi:10.1007/s00167-010-1238-6

14. Franklin S, Cook J. Prospective trial of autologous conditioned plasma versus hyaluronan plus corticosteroid for elbow osteoarthritis in dogs. Can Vet J (2013) 54:881-4

15. Jang SJ, Kim JD, Cha SS. Platelet-rich plasma (PRP) injections as an effective treatment for early osteoarthritis. Eur J Orthop Surg Traumatol (2013) 23:573-80. doi:10.1007/s00590-012-1037-5

16. Khoshbin A, Leroux T, Wasserstein D, Marks P, Theodoropoulos J, OgilvieHarris D, et al. The efficacy of platelet-rich plasma in the treatment of symptomatic knee osteoarthritis: a systematic review with quantitative synthesis. Arthroscopy (2013) 29(12):2037-48. doi:10.1007/s00167-013-2743-1

17. Kon E, Buda R, Filardo G, Di Martino A, Timoncini A, Cenacchi A, et al. Platelet-rich plasma: intra-articular knee injections produced favorable results on degenerative cartilage lesions. Knee Surg Sports Traumatol Arthrosc (2010) 18:474-9. doi:10.1007/s00167-009-0940-8

18. Kon E, Mandelbaum B, Buda R, Filardo G, Delcogliano M, Timoncini A, et al. Platelet-rich plasma intra-articular injection versus hyaluronic acid viscosupplementation as treatments for cartilage pathology: from early degeneration to osteoarthritis. Arthroscopy (2011) 27(11):1490-501. doi:10.1016/j.arthro.2011. 05.011

19. McCarrel T, Fortier L. Temporal growth factor release from platelet-rich plasma, trehalose lyophilized platelets, and bone marrow aspirate and their effect on tendon and ligament gene expression. J Orthop Res (2009) 27(8):1033-42. doi:10.1002/jor.20853

20. McCarrel TM, Minas T, Fortier LA. Optimization of leukocyte concentration in platelet-rich plasma for the treatment of tendinopathy. J Bone Joint Surg Am (2012) 94(1-8):e143. doi:10.2106/JBJS.L.00019

21. Mishra A, Pavelko T. Treatment of chronic elbow tendinosis with buffered platelet-rich plasma. Am J Sports Med (2006) 34(11):1774-8. doi:10.1177/ 0363546506288850

22. Patel S, Shillon MS, Aggarwal S, Marwaha N, Jain A. Treatment with plateletrich plasma is more effective than placebo for knee osteoarthritis: a prospective, double-blinded, randomized trial. Am J Sports Med (2013) 41(2):356-64. doi: $10.1177 / 0363546512471299$

23. Raeissadat SA, Rayegani SM, Babaee M, Ghorbani E. The effect of platelet-rich plasma on pain, function, and quality of life of patients with knee osteoarthritis. Pain Res and Treatment (2013) 1:1-7. doi:10.1155/2013/165967

24. Randelli P, Arrigoni P, Ragone V, Aliprandi A, Cabitza P. Platelet rich plasma in arthroscopic rotator cuff repair: a prospective RCT study, 2-year follow-up. J Shoulder Elbow Surg (2011) 20:518-28. doi:10.1016/j.jse.2011.02.008

25. Sampson S, Gerhardt M, Mandelbaum B. Platelet rich plasma injection grafts for musculoskeletal injuries: a review. Curr Rev Musculoskelet Med (2008) 1:165-74. doi:10.1007/s12178-008-9032-5

26. Silva RF, Carmona JU, Rezende CMF. Intra-articular injections of autologous platelet concentrates in dogs with surgical reparation of cranial cruciate ligament rupture. Vet Comp Orthop Traumatol (2013) 26:122-5. doi:10.3415/ VCOT-12-06-0075

27. Smith JJ, Ross MW, Smith RKW. Anabolic effects of acellular bone marrow, platelet rich plasma, and serum on equine suspensory ligament fibroblasts in vitro. Vet Comp Orthop Traumatol (2006) 19:43-7.

28. Souza TFB, Andrade AL, Ferrreira GTNM, Sakamoto SS, Albuquerque VB, Bonfim SRM, et al. Healing and expression of growth factors (TGF-B and PDGF) in canine radial osteotomy gap containing platelet-rich plasma. Vet Comp Orthop Traumatol (2012) 25:445-52. doi:10.3415/VCOT-10-10-0146

29. Van Buul GM, Koevoet WLM, Kops N, Bos PK, Verhaar JAN, Weinans $\mathrm{H}$, et al. Platelet-rich plasma releasate inhibits inflammatory processes in osteoarthritic chondrocytes. Am J Sports Med (2011) 39(11):2362-70. doi:10. $1177 / 0363546511419278$

30. Xie X, Hua W, Zhao S, Xie G, Huangfu X, Zhao J. The effect of plateletrich plasma on patterns of gene expression in a dog model of anterior cruciate ligament reconstruction. J Surg Res (2013) 180:80-8. doi:10.1016/j.jss. 2012.10.036

31. Xie X, Wang Y, Zhao C, Guo S, Liu S, Jia W, et al. Comparative evaluation of MSCs from bone marrow and adipose tissue seeded in PRP-derived scaffold for cartilage regeneration. Biomaterials (2012) 33:7008-18. doi:10.1016/j. biomaterials.2012.06.058

32. Broeckx S, Zimmerman M, Crocetti S, Suls M, Marien T, Ferguson SJ, et al. Regenerative therapies for equine degenerative joint disease: a preliminary study. PLoS One (2014) 9(1):e85917. doi:10.1371/journal.pone.0085917

33. Cho HS, Song IH, Park SY, Sung MC, Ahn MW, Song KE. Individual variation in growth factor concentrations in platelet-rich plasma and its influence on human mesenchymal stem cells. Korean J Lab Med (2011) 31:212-8. doi:10. 3343/kjlm.2011.31.3.212

34. Del Bue M, Riccò S, Ramoni R, Conti V, Gnudi G, Grolli S. Equine adiposetissue derived mesenchymal stem cells and platelet concentrates: their association in vitro and in vivo. Vet Res Commun (2008) 32(S1):S51-5. doi:10.1007/ s11259-008-9093-3

35. Drengk A, Zapf A, Stürmer EK, Stürmer KM, Frosch KH. Influence of plateletrich plasma on chondrogenic differentiation and proliferation of chondrocytes and mesenchymal stem cells. Cells Tissues Organs (2009) 189:317-26. doi:10. $1159 / 000151290$

36. Dohan Ehrenfest DM, Rasmusson L, Albrektsson T. Classification of platelet concentrates: from pure platelet-rich plasma (P-PRP) to leukocyte- and plateletrich fibrin (L-PRF). Trends Biotech (2008) 27(3):158-67. doi:10.1016/j.tibtech 2008.11.009

37. Mishra A, Tummala P, King A, Lee B, Kraus M, Tse V, et al. Buffered plateletrich plasma enhances mesenchymal stem cell proliferation and chondrogenic differentiation. Tissue Eng Part C Methods (2009) 15:431-5. doi:10.1089/ten.tec. 2008.0534

38. Schnabel LV, Lynch ME, Van der Meulen MC, Yeager AE, Komatowski MA, Nixon AJ. Mesenchymal stem cells and insulin-like growth factor-I 
gene-enhanced mesenchymal stem cells improve structural aspects of healing in equine flexor digitorum superficialis tendons. J Orthop Res (2009) 27(10):1392-8. doi:10.1002/jor.20887

39. Torricelli P, Fini M, Filardo G, Tschon M, Pischedda M, Pacorini A, et al. Regenerative medicine for the treatment of musculoskeletal overuse injuries in competition horses. Internat Orthop (2011) 35:1569-76. doi:10.1007/s00264011-1312-9

40. Braun HJ, Kim HJ, Chu CR, Dragoo JL. The effect of platelet-rich plasma formulations and blood products on human synoviocytes. Am J Sports Med (2014) 42(5):1204-10. doi:10.1177/0363546514525593

41. Sundman EA, Cole BJ, Fortier LA. Growth factor and catabolic cytokine concentrations are influenced by the cellular composition of platelet-rich plasma. Am J Sports Med (2013) 39(10):2135-40. doi:10.1177/0363546511417792

42. Sundman EA, Boswell SG, Schnabel LV, Mohammed HO, Minas T, Fortier LA. Increasing platelet concentrations in leukocyte-reduced platelet-rich plasma decrease collagen gene synthesis in tendons. Am J Sports Med (2013) 42(1):35-41. doi:10.1177/0363546513507766

43. Castillo TN, Pouliot MA, Kim HJ, Dragoo JL. Comparison of growth factor and platelet concentrations from commercial platelet-rich plasma separation systems. Am J Sports Med (2011) 39(2):266-71. doi:10.1177/0363546510387517

44. Stief M, Gottschalk J, Ionita JC, Einspanier A, Oechtering G, Boettcher P. Concentration of platelets and growth factors in canine autologous conditioned plasma. Vet Comp Orthop Traumatol (2011) 24:285-90. doi:10.3415/VCOT-1004-0064

45. Boswell SG, Schnabel LV, Mohammed HO, Sundman EA, Minas T, Fortier LA. Increasing platelet concentrations in leukocyte-reduced platelet-rich plasma decrease collagen gene synthesis in tendons. Am J Sports Med (2013) 42(1):42-9. doi:10.1177/0363546513507566

46. Cavallo C, Filardo G, Mariani E, Kon E, Marcacci M, Pereira Ruiz MT, et al. Comparison of platelet-rich plasma formulations for cartilage healing. J Bone Joint Surg Am (2014) 96:423-9. doi:10.2106/JBJS.M.00726

47. Naldini A, Morena E, Fimiani M, Campoccia G, Fossombroni V, Carroro F. The effects of autologous platelet gel on inflammatory cytokine response in human peripheral blood mononuclear cells. Platelets (2008) 19(4):268-74. doi:10.1080/09537100801947426

48. Yoshida R, Murray MM. Peripheral blood mononuclear cells enhance the anabolic effects of platelet-rich plasma on anterior cruciate ligament fibroblasts. J Orthop Res (2013) 31(1):29-34. doi:10.1002/jor.22183

49. Franklin SP, Garner BC, Cook JL. Characteristics of canine platelet-rich plasma prepared with five commercially available systems. Am J Vet Res (2015) 76(9):822-7. doi:10.2460/ajvr.76.9.822

Conflict of Interest Statement: Regenerative medicine products and systems were received from the companies below for system validation and clinical testing: Arthrex, EmCyte, Harvest, PulseVet, and Canine Regenerative Therapies.

Copyright (c) 2016 Carr, Canapp, Mason, Cox and Hess. This is an open-access article distributed under the terms of the Creative Commons Attribution License (CC BY). The use, distribution or reproduction in other forums is permitted, provided the original author(s) or licensor are credited and that the original publication in this journal is cited, in accordance with accepted academic practice. No use, distribution or reproduction is permitted which does not comply with these terms. 